\title{
Psychological structure of personal resources of coping behavior of high school students
}

\author{
Elena Suroedova ${ }^{1, *}$, Galina Uvarova $^{2}$, and Nogala Shevkieva ${ }^{2}$ \\ ${ }^{1}$ Don State Technical University, Ploshchad' Gagarina, 1, 344002 Rostov-on-Don, Russia \\ ${ }^{2}$ Kalmyk State University named after B. B. Gorodovikova, Ulitsa Pushkina, 11, 358000 Elista, \\ Republic of Kalmykia
}

\begin{abstract}
The article is devoted to the study of the structure of personal resources of coping behavior in high school students with low and medium levels of stress resistance. The study involved 70 high school students aged $16-17$ years $(\mathrm{M}=17,1 \mathrm{SD}=1,1(44,2 \% \mathrm{men}))$. The study was carried out on the basis of the Kalmyk ethnocultural gymnasium named after I. ZayaPandita and Trinity Gymnasium named after B. B. Gorodovikov. The study used the following methods: «Test of self-assessment of stress tolerance» (S. Cowhen, G. Willianson), «Test for optimism» (C. Scheyer, M. Carver, adaptation of O.A. Sychev), methodology «Scale of general self-efficacy» (R. Schwarzer, M. Erusalema, adaptation of V. Romek), the method «Brief scale of self-control» (J. Tangney, R. Baumeister, A. L. Boone, adaptation of T.O. Gordeeva, E.N. Osina, D.D. Suchkova, T.Yu. Ivanova, O.A. Sycheva, V.V. Bobrova), «Questionnaire of selforganization of activity» (E.Yu. Mandrikova), «Methods for diagnosing reflexivity» (A.V. Karpov, V.V. Ponomareva). The methods of mathematical and statistical processing of empirical data were: correlation analysis (r-Spearman), structural - psychological analysis according to generalized indicators of the index of organization, integrativity and differentiation of the structure (A.V. Karpov), the express- $\mathrm{s}^{2}$ method for comparing matrices and structuralograms for their «homogeneityheterogeneity» (A.V. Karpov). It was found that the basic components that ensure the structural integration of the system of personal resources of coping behavior in the subgroup of high school students with an average level of stress resistance are: optimism; purposefulness; situational reflection; self-control. Research prospects are aimed at further studying the factors and predictors of the personal psychological resources of schoolchildren in overcoming difficult life situations and making recommendations to school psychologists on the development of programs aimed at developing the skills of reflection, self-regulation and self-control in stressful situations in students.
\end{abstract}

\section{Introduction}

\footnotetext{
* Corresponding author: suroedova@mail.ru
} 
Coping behavior is an essential component of the adaptive social behavior of an individual and is significant in connection with the ongoing social instability in modern society. In such conditions, one of the most vulnerable age groups are people of adolescence, who face the important life task of making a choice that is reflected in personal, social and professional self-determination. And the well-being of the individual in the future depends on how successful coping will be at this age.

The effectiveness of coping behavior is largely mediated precisely by resources that begin to actively act already at the stage of cognitive assessment of the stressfulness of the situation. The resources of coping behavior not only contribute to a better understanding of a difficult life situation, but also to improve the emotional state, strengthen the self-concept and a positive image of the self, contact with others, increase the feeling of one's own competence, increase self-efficacy, restore existing resources and find new ones.

In foreign psychology, the problem of resources has been studied for 40 years (W. Aycock, W.L. Curlette, K.B. Matheny, G.N. Juncer, St. Hobfoll, W.B. Schaufeli). In these studies, a resource is referred to as a factor that contributes to the successful adaptation of a person to the world and performs a compensatory function of resisting stress and reducing the risk of developmental disorders. Dariusz Krok et al. propose to consider personal resources as personality characteristics that are valued by a person and are able to improve his / her effective functioning in terms of control and impact on the environment [1]. In Russian psychology B.G. Ananyev was the first to draw attention to the resource problem. At this time, the concept of «resource» is used by T.V. Kornilova (general psychological work), E.A. Sergienko (developmental psychology), D.A. Leontiev (personality psychology), V.A. Bodrov (psychology of stress). The resources are analyzed by K.A. Abulkhanova and L.I. Antsyferova as an aspect of describing life strategies, V.A. Bodrov, T.L. Kryukova, E.Yu. Kozhevnikova, E.A. Petrova as a factor in overcoming stress. V.A. Bodrov, D.A. Leontiev, E.Yu. Kozhevnikov considers personality traits as resources [2]. In the works of V.A. Bodrov considers a resource in three versions: a resource as a material phenomenon, a physical or chemical process in an organism; resource as a theoretical construct; resource as a set of variables that ensure a stable level of performance of tasks for a certain time [3].

Andersson M.A., dealing with the problem of human use of personal resources during crises, allocates social and psychological natural resources. Psychological resources are facets of the personality that shape the ability to cope with life's circumstances. The author, based on the research of Caplan, Leslie J., Carmi Schooler, believes that self-esteem and personal mastery are included in the structure of personal resources. Both senses are designed to reinforce a sense of effectiveness in difficult times, based on effective coping methods and strategies. However, the author notes that stress can lead to a decrease in selfconfidence and, thus, to a decrease in certain psychological resources [4]. In our work, we will focus on considering the psychological natural resources of the individual in overcoming stress and difficult life events.

The choice of effective strategies and methods for resolving a problem situation is closely related to the cognitive personality traits: the specificity of the perception of events, attention and memory, thought processes and imagination. We believe that the cognitive abilities of an individual play a key role in overcoming difficult situations and the formation of a personality's stress resistance. As noted by M.A. Cold, this idea is fundamentally important for understanding the nature of human potential [5] in which both intellectual and creative abilities of an individual are important. An individual cognitive resource acts as a mechanism for the interconnection of intellectual (convergent) and creative (divergent) abilities and manifests itself in any life situations and spheres of activity. The cognitive resource can meet the requirements of the task and then focuses on the main solution, manifesting itself as a convergent ability. If this resource exceeds the 
requirements of the task, then the scope of intellectual activity expands and it becomes possible to perform many other tasks. Then the resource manifests itself as a divergent ability. This gives rise to the prospect of analyzing cognitive abilities as manifestations of a single intellect, interpreted as an individual mental resource [5].

A person's ability to reflect can be attributed to the cognitive (mental) resource.

For example, Archer M.S. considers reflexivity as an internal dialogue, in which a person evaluates his social and institutional context as a means of bypassing structural constraints [6]; A. Giddens emphasizes that the ability to reflect allows people to make constant changes in their lives in response to knowledge about social circumstances; Myers characterizes reflexivity as something that a person develops [7].

Archer M.S. describes reflection as a reflection that helps people assess their social context, present possible alternatives for their actions, and work with others to make collaborative activities effective. From the point of view of Archer M.S., reflexivity is the ability of an individual to build strategies of behavior and activity that allow taking into account the position of the individual in the social system and acting with the help of tactical and strategic thinking [6].

In modern science, reflection is conceptualized and presented as a cognitive process in which a person applies logical thinking to the analysis of the situation and / or himself in order to achieve the final result. This requires the individual to reflect on the outside world, to realize that people are embedded in society and form, with others, a joint life and social experience $[8,9]$.

In addition to the cognitive component of personal resources in overcoming difficult life situations, it is necessary to highlight the regulatory-volitional aspect, which is most often represented through the volitional qualities of the individual. In the studies of Glazunov Y.T. and Sidorov K.R. volitional quality denotes a specific way of manifestation of volitional regulation, due to the nature of the difficulty to be overcome. Each volitional quality has its own characteristics, and the power of the expression of will consists of the forces of the volitional qualities that make it up. The authors call the power of volitional qualities the measure of a person's mental ability to induce voluntary actions in spite of the circumstances [10-12].

It should be noted right away that the will manifests itself in the regulation of other mental functions of a person: perception, memory, thinking, i.e. closely related to the cognitive properties of the individual. Volitional qualities are used to compensate for the internal qualities of the subject that are not conducive to activity, such as impulsivity, inertia, etc. At the same time, Glazunov Y.T. and Sidorov K.R. we notice that the will mainly implements three functions: incentive, providing the beginning of mental or physical actions; stabilizing, associated with maintaining the activity of the individual; inhibiting, consisting in restraining motives that are not consistent with the general purpose of the activity. All of the above serves to increase the efficiency of human activity [13].

Vincenza Capone, Daniela Caso, Anna Rosa Donizzetti and Fortuna Procentese investigated a person's ability to cope with difficult life situations in terms of self-efficacy and self-regulation. The authors believe that self-efficacy is able to regulate the relationship between stressor and stress in disagreement with the needs and resources of the individual (including in the educational sphere) [14] and acts as one of the factors protecting academic performance. Bandura A. called this component «Belief in one's ability to organize and perform the actions necessary to produce desired accomplishments» and argued that pursuing meaningful goals and achieving them are important components of adaptive selfregulation and positively affect overall health and well-being [6]. In addition, several studies [15-17] have demonstrated the inhibitory role of academic self-efficacy, defined as the belief that people can successfully perform assigned academic tasks by being aware of 
and adopting effective strategies related to academic commitment and in assessing the problems being solved [18].

Self-control is a special form of self-regulation, but not all forms of self-regulation include self-control $[19,20]$. Inzlicht et al. defines self-control as the targeting of behavior to a desired goal $[21,22]$, a process that includes both inhibitory and initiating components and is closely related to the implementation of behavior [23-26]. Self-control can therefore be described as the ability to alter or reverse competing response tendencies, as well as to regulate behavior, thought, and emotion according to a desired goal, and is used to stimulate desired responses and suppress unwanted responses or impulsive actions [24, 27]. Bermudez J.P. indicates that self-control is not just a psychological ability, but rather a complex coordinated structure of abilities designed to perform a controlling function. Such a complex of polypower belongs to the category of skills, and not to the category of unambiguous resource opportunities [27]. Researcher Shenhav, A. et al. indicate the relationship of self-control with cognitive functions. The authors argue that self-control consists of a series of organized cognitive control processes aimed at overcoming the propensity for automatic responses that are inconsistent with commitments. Cognitive control is a set of higher-order cognitive functions designed to develop purposeful behavior, especially when this requires overcoming competing response tendencies. It has three key functions: tracking conflicting signals; choice of control strategy; implementation of the management strategy [28].

In the works of Bermudez J.P., Li J.B., Leung I.T.Y., Li Z.X., self-control appears as a decisive factor that contributes to improving people's productivity by encouraging positive thoughts, emotions and behavior, as well as preventing negative opposites [27, 29].

The educational process and academic tasks place high demands on students not only for cognitive functions, but also for the formation of volitional qualities. A number of foreign studies have shown the relationship between academic success and the regulatoryvolitional qualities of schoolchildren and students. Duckworth A.L. and Quinn P.D. defining resilience [30] «as passion and perseverance in achieving long-term goals» refer it to the level of drive that people demonstrate to achieve their goals during long-term activities. Perseverance and tenacity is reflected at the level of personality traits as a passion for achieving long-term goals. Consequently, the authors conclude, resilience is manifested by hard work towards achieving challenging goals, sustaining effort and interest over the years, despite failures in the learning process. In the studies of Credé M., Tynan M.C., Harms P.D. shows the relationship of persistence with social achievements and results of young people and adults, such as satisfaction with the profession, activity, career [31]. Therefore, it can also be associated with positive learning outcomes, student achievement.

Studies show that there is another factor closely related to cognitive characteristics and regulatory-volitional qualities, which are part of the structure of personal resources. We believe that these are individual and personal characteristics of a person. The variety of individual and personal properties of a person does not allow us to consider everything and their influence on stress resistance and the formation of coping strategies of behavior in difficult situations.

Lourdes Rey et al., studying the problem of depression and bullying, notes that there are several well-known factors that, if present, permanently reduce the risk of illness. These personal resources include emotional intelligence, gratitude, forgiveness and optimism [32].

Andersson M.A. researches the influence of optimism on a person's ability to overcome difficulties and withstand stress. The author, drawing on the research of Carver, Charles S., Jennifer Connor Smith, Solberg Nes, defines dispositional optimism as a stable expectation that good events will occur in a variety of difficult life situations. Expectation of good events is associated with focusing on the positive aspects of difficult situations and successfully overcoming difficult situations, even despite anxiety and physiological stress. 
Whereas psychological resources such as self-esteem and personal skill are fickle and in situations of social stress cannot consistently maintain effective coping [4].

E.A. Petrova notes that human resources are interconnected and represent a system where the effect of coping is a system-forming factor. The resource system is included as a structural component in the subject's coping behavior system, the purpose of which is the adaptive effect. Within the resource system itself, subsystems of personal and environmental resources can be distinguished [33].

E.A. Petrova allocates such personal resources as a sense of success and self-realization, optimism, humor, the ability to communicate effectively, self-discipline, a sense of independence [33].

It has been established that optimism, a subjective feeling of personal effectiveness, self-control, reflexivity, planning, purposefulness and perseverance are important personal resources for coping behavior in high school students [34].

There is still no answer to the question of how the system of personal resources functions, it is not clear whether specificity is found in the structure of personal resources of coping behavior in high school students with different levels of stress resistance.

Optimism (Andersson M.A., Carver Charles S., Jennifer Connor Smith, Solberg Nes, Rey L., Quintana-Orts C., Mérida-López S., Extremera N.), self-efficacy (Vincenza Capone, Daniela Caso, Anna Rosa Donizzetti, Fortuna Procentese, Bodrov V.A., Bandura A.), self-control (Fujita K., Inzlicht M., Gutsell J.N., Werne, K.M., Briskin J., Roberts B., de Ridder D.T., de Boer B. J., Lugtig P., Bakker A.B., van Hooft E.A., Gillebaart M., Baumeister R.F., Bodrov V.A., Gordeeva T.O., Osin E.N., Suchkov D.D., Ivanova T. Yu., Sychev O.A., Bobrov V.V.), reflexivity (Archer M.S., Myers K.C., Golob T, Makarovič M., Rek M.), volitional qualities (Duckworth A.L., Quinn P.D., Credé M., Tynan M.C., Harms P.D., Glazunov Y.T., Sidorov K.R., Khazova S.A.). The choice of the listed personal formations was carried out on the basis of Russian and foreign studies, also due to the interest of the researcher, since the resources have a systemic organization (S.A. Khazova) [35].

The aim of the study was to study the features of the structural organization of personal resources of coping behavior in high school students with different levels of stress resistance.

The hypothesis was the assumption that there are significant differences in the structural organization of such personal resources of coping behavior as indicators of optimism, selfefficacy, self-control, components of reflection, purposefulness and perseverance in high school students with different levels of stress resistance.

\section{Materials and methods}

The study involved 70 respondents (16-17 years old), boys - 31, girls - 39 . The study was conducted on the basis of the Kalmyk ethnocultural gymnasium named after Zaya-Pandita and Trinity Gymnasium named after B. B. Gorodovikov.

The study used the following methods: «Test of self-assessment of stress tolerance» (S. Cowhen, G. Willianson), «Test for optimism» (C. Scheyer, M. Carver, adaptation of O.A. Sychev), methodology «Scale of general self-efficacy» (R. Schwarzer, M. Erusalema, adaptation of V. Romek), the method «Brief scale of self-control» (J. Tangney, R. Baumeister, A.L. Boone, adaptation of T.O. Gordeeva, E.N. Osina, D.D. Suchkova, T.Yu. Ivanova, O.A. Sycheva, V.V. Bobrova), "Questionnaire of self-organization of activity» (E.Yu. Mandrikova), «Methods for diagnosing reflexivity» (A.V. Karpov, V.V. Ponomareva).

Mathematical and statistical methods for processing empirical data: correlation analysis (r-Spearman), structural and psychological analysis according to generalized indicators of 
the index of organization, integrativity and differentiation of the structure (A.V. Karpov), the method of express- $\mathrm{x}^{2}$ for comparing matrices and structograms on their «homogeneityheterogeneity» (A.V. Karpov).

\section{Results}

The entire sample $(\mathrm{N}=70)$ was differentiated into two subgroups depending on the level of stress resistance: the average level of stress resistance $(\mathrm{N}=31)$ and a low level of stress resistance $(\mathrm{N}=39)$. Then the procedure of multivariate correlation analysis of the measured indicators was carried out. The intercorrelation matrices of indicators were studied and, on their basis, structuralograms of significantly correlated measured indicators were created, the indices of structural organization were calculated (coherence index, divergence index and structure organization index

Figure 1 shows the structogram of coping behavior personality resources for a subgroup of high school students with an average level of stress resistance.

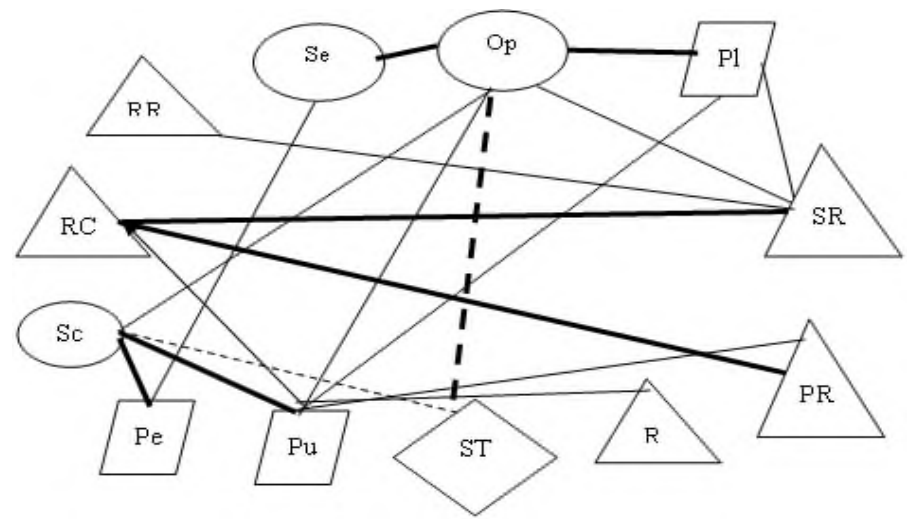

Fig. 1. Structogram of personal resources of coping behavior in high school students with an average level of stress resistance

Symbols: Op - optimism; Se - self-efficacy; Sc - self-control; RR - retrospective reflection; $\mathrm{SR}$ - situational reflection, PR - perspective reflection; RC - reflection of communication; R - reflexivity; Pl - planarity; Pu - purposefulness; Pe - persistence, ST - stress tolerance.

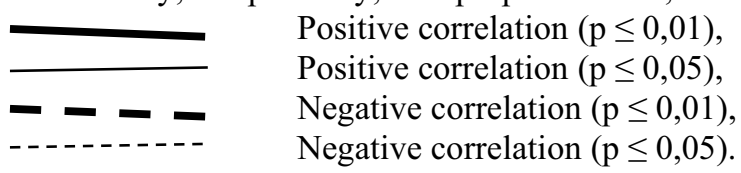

Figure 2 shows a structogram of coping behavior personality resources for a subgroup of high school students with a low level of stress resistance/ 


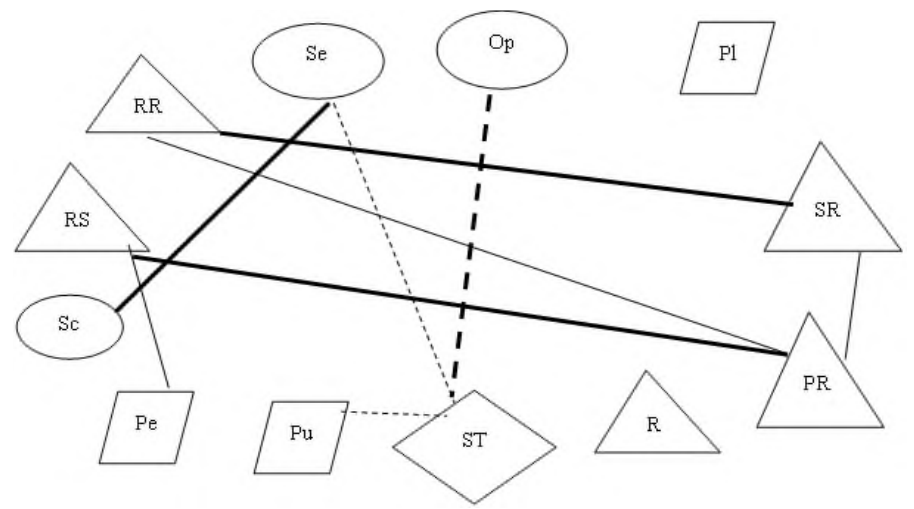

Fig. 2. Structogram of personal resources of coping behavior of high school students with a low level of stress resistance

Symbols: Op - optimism; Se - self-efficacy; Sc - self-control; RR - retrospective reflection; $\mathrm{SR}$ - situational reflection, $\mathrm{PR}$ - perspective reflection; RC - reflection of communication; R - reflexivity; Pl - planarity; Pu - purposefulness; Pe - persistence, ST - stress tolerance.

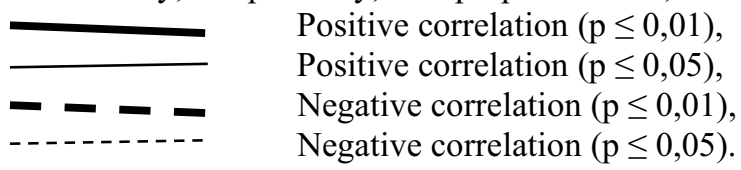

On the basis of the data presented, the values of the indices of the structural organization of the measured indicators were calculated in the subgroup of high school students with an average level of stress resistance and in the subgroup of high school students with a low level of stress resistance. The results are shown in Table 1.

Table 1. The values of the indices of the structural organization of personal resources of coping behavior in high school students with different levels of stress resistance

\begin{tabular}{|c|c|c|}
\hline \multirow[t]{2}{*}{ Indexes } & \multicolumn{2}{|c|}{ Stress tolerance level } \\
\hline & Middle & Low \\
\hline Coherence structure & 41 & 15 \\
\hline Divergence of structure & 5 & 7 \\
\hline $\begin{array}{l}\text { Index of general organization } \\
\text { of the structure }\end{array}$ & 46 & 22 \\
\hline
\end{tabular}

Based on the presented structureograms, the basic components were established in the structure of the measured indicators in the subgroup of high school students with an average level of stress resistance and in the subgroup of high school students with a low level of stress resistance. The results are shown in Table 2.

Table 2. Weighted values of indicators of personal resources of coping behavior in high school students with different levels of stress resistance

\begin{tabular}{|c|c|c|c|c|c|c|}
\hline \multirow[t]{3}{*}{ Indicators } & & \multicolumn{2}{|c|}{ Average leve } & & \multicolumn{2}{|c|}{ High leve } \\
\hline & \multicolumn{6}{|c|}{ Component structural weight $(\mathrm{W})$} \\
\hline & + & - & $\Sigma$ & + & - & $\Sigma$ \\
\hline Optimism & 12 & 3 & 15 & 0 & 3 & 3 \\
\hline Self-efficacy & 5 & 0 & 5 & 3 & 2 & 5 \\
\hline
\end{tabular}




\begin{tabular}{|l|l|l|l|l|l|l|}
\hline Self-control & 8 & 2 & 10 & 3 & 0 & 3 \\
\hline Retrospective reflection & 2 & 0 & 2 & 5 & 0 & 5 \\
\hline Situational reflection & 12 & 0 & 12 & 5 & 0 & 5 \\
\hline Perspective reflection & 8 & 0 & 8 & 7 & 0 & 7 \\
\hline Reflection of communication & 9 & 0 & 8 & 5 & 0 & 5 \\
\hline Reflexivity & 2 & 0 & 2 & 0 & 0 & 0 \\
\hline Planarity & 7 & 0 & 7 & 0 & 0 & 0 \\
\hline Purposefulness & 13 & 0 & 13 & 0 & 2 & 2 \\
\hline Persistence & 5 & 0 & 5 & 2 & 0 & 2 \\
\hline Stress tolerance & 0 & 5 & 5 & 0 & 7 & 7 \\
\hline
\end{tabular}

At the final stage of the implementation of the method of structural-psychological analysis, a qualitative analysis was carried out, matrices and structuralograms were compared for their «homogeneity-heterogeneity». For these purposes, the express- $\mathrm{x}^{2}$ method was used. The results are shown in Table 3.

Table 3. Comparison of intercorrelation matrices of indicators of personal resources of coping behavior in high school students with different levels of stress resistance according to the criterion of express- $\mathrm{x}^{2}$

\begin{tabular}{|l|l|l|}
\hline & $\begin{array}{l}\text { Average level of stress } \\
\text { resistance }\end{array}$ & $\begin{array}{l}\text { High level } \\
\text { stress resistance }\end{array}$ \\
\hline $\begin{array}{l}\text { Average level of } \\
\text { stress resistance }\end{array}$ & 1,000 & \\
\hline $\begin{array}{l}\text { High level } \\
\text { stress resistance }\end{array}$ & $\begin{array}{l}\mathrm{r}=0,007 \\
\mathrm{p}=0,982\end{array}$ & 1,000 \\
\hline
\end{tabular}

\section{Discussion}

In the subgroup of high school students with an average level of stress resistance (Figure 1), positive links were established between the indicators of optimism, purposefulness, situational reflection, and self-control. The indicator of optimism is positively associated with self-efficacy $(p=0,002)$, self-control $(p=0,024)$, situational reflection $(p=0,021)$, orderliness $(p=0,003)$, purposefulness $(p=0,030)$. Purposefulness is associated with selfcontrol $(p=0,001)$, perspective reflection $(p=0,030)$, reflection of communication and interaction with others $(p=0,029)$, reflexivity $(p=0,017)$, orderliness $(p=0,029)$. It should be noted that the greatest number of connections with reflection shows purposefulness, which positively correlates with two types of reflection and reflexivity. Persistence is positively correlated with self-efficacy $(p=0,046)$ and self-control $(p=0,000)$. Planning reveals a positive relationship with situational reflection $(p=0,037)$. Situational reflection is positively correlated with all types of reflection. Negative relationships were found between the indicator of stress resistance and indicators of optimism $(p=0,004)$, selfcontrol $(\mathrm{p}=0,021)$.

In a subgroup of high school students with a low level of stress resistance (Figure 2), it was found that self-efficacy is positively associated with self-control $(p=0,000)$. A positive relationship was revealed between persistence and reflexion of communication and 
interaction with others $(\mathrm{p}=0,045)$. Perspective reflection is positively correlated with all types of reflection. Negative relationships were found between the stress tolerance indicator and the indicators of optimism $(\mathrm{p}=0,001)$, self-efficacy $(\mathrm{p}=0,015)$, purposefulness $(\mathrm{p}=$ $0,044)$.

It is very interesting that the indicators of orderliness and reflexivity do not show statistically significant relationships with the measured indicators (in the subgroup of high school students with an average level of stress resistance, the relationships of these indicators were revealed). It should also be noted that the indicator of optimism only negatively correlates with the indicator of stress resistance, and in the subgroup of high school students with an average level of stress resistance, it shows a positive relationship with self-efficacy, self-control, situational reflection, orderliness and purposefulness.

It should be noted that in the subgroup of senior pupils with an average level of stress resistance, the number of connections was found $-19(\mathrm{p} \leq 0,05$ and $\mathrm{p} \leq 0,01)$, in the subgroup of senior pupils with a low level of stress resistance - the number of connections - 9 ( $p \leq 0,05$ and $\mathrm{p} \leq 0,01)$.

An analysis of the values of the indices of the structural organization of coping behavior personal resources in senior students with different levels of stress resistance (Table 1) showed that the degree of coherence (integration) of the structure in the subgroup of high school students with an average level of stress resistance is 2.73 times higher than in the subgroup of high school students with a low level of stress resistance. stress resistance. It can be argued that in the subgroup of high school students with an average level of stress resistance, the integrative mechanisms of the structure of indicators of optimism, purposefulness, situational reflection, self-control, perspective reflection, reflection of communication and interaction with others, orderliness, persistence of self-efficacy, retrospective reflection and reflexivity are more pronounced.

In terms of the degree of structure divergence, subgroups with different levels of stress resistance do not differ.

As part of the study, it was found that the highest level of structural organization of the measured indicators is observed in the subgroup of high school students with an average level of stress resistance. It can be argued that in the subgroup of high school students with an average level of stress resistance, the components are more "cohesive", forming a holistic structure of personality traits that contribute to coping with many difficult situations, transforming them or adapting to them.

On the basis of the presented structureograms, the basic components were established in the structure of the measured indicators in the subgroup of high school students with an average level of stress resistance and in the subgroup of high school students with a low level of stress resistance. It was found that the basic components that ensure the structural integration of the system of personality traits in the subgroup of high school students with an average level of stress resistance are: optimism $(\mathrm{W}=15)$; purposefulness $(\mathrm{W}=13)$; situational reflection $(\mathrm{W}=12)$; self-control $(\mathrm{W}=10)$. Consequently, in a stressful situation in a subgroup of high school students with an average level of stress resistance, the following mechanisms are triggered: high school students strive to analyze the current events, assessing the stressful situation and the available opportunities to overcome it, hope for the best development of events, set specific goals, purposefully strive for achieving goals, while refraining from maladaptive behavior, demonstrating less susceptibility to stress.

Optimism, dedication, situational reflection and self-control positively correlate with the rest of the measured indicators, in this regard, in a difficult situation, the entire system of interrelated components is «launched», which allows high school students to perceive a difficult situation not as stressful, but as a challenge. 
As follows from the presented results, in the subgroup of high school students with a low level of stress resistance there are no basic components that would ensure the structural integration of the system.

The structures of the components of personal properties in the subgroup of high school students with an average level of stress resistance and in the subgroup of high school students with a low level of stress resistance differ qualitatively (and not only in the degree of their organization) from each other in the content of interrelationships within them, therefore, they are heterogeneous (table 3 ).

The results obtained are consistent with the results of a study by foreign psychologists.

Alacorn, Bowling, and Khazon analyzed the psychological phenomenon of optimism and its role as a means of reducing stress and coping with difficult life situations. Thus, optimism is positively correlated with life satisfaction, happiness, and mental and physical well-being, and negatively correlated with depression and anxiety [36]. Another study by Aspinwall and Taylor (1992), showed that optimism is associated with higher academic performance.

In studies by Duckworth A.L., and Quinn P.D. it is shown that persistence and perseverance are predictors of educational interest and student orientation towards achieving a long-term goal in educational activities. In a recent study of teenage students, Hagger, M.S. and Hamilton, K. [37] demonstrated a positive contribution of volitional effort to student achievement. «Strong-willed» students are those who devote a lot of time to achieving goals and objectives, demonstrate patterns of behavior and focus on results. Of the two volitional characteristics (persistence and passion), research results tend to point to persistence as a relatively stronger predictor of long-term goals. Under unfavorable circumstances, which include objective failure or a subjective feeling of failure, the person stops continuing to improve and is not active in achieving the goal [37]. In accordance with these findings, Guo, J. and colleagues [38] found differentiated patterns of correlation between persistence factors and various psychological variables (eg, motivation) [39].

\section{Findings}

Structural analysis indicates the presence of a qualitative specificity of the structure of personal resources of coping behavior (parameters of optimism, self-efficacy, self-control, reflexivity, orderliness, purposefulness and perseverance) in the subgroup of high school students with an average level of stress resistance, in contrast to the structure of personal resources of coping behavior in the subgroup of high school students with a low level stress resistance.

The degree of coherence of the structure of personal resources of coping behavior in the subgroup of high school students with an average level of stress resistance is 2.73 times higher than in the subgroup of high school students with a low level of stress resistance. The highest level of structural organization of the measured indicators is observed in the subgroup of high school students with an average level of stress resistance.

The basic components that ensure the structural integration of the system of personal resources of coping behavior in the subgroup of high school students with an average level of stress resistance are: optimism, purposefulness, situational reflection, self-control. In the subgroup of high school students with a low level of stress resistance, there are no basic components that would ensure the structural integration of the system.

The structures of coping behavior personal resources in the subgroup of high school students with an average level of stress resistance and in the subgroup of high school students with a low level of stress resistance are heterogeneous.

Consequently, the hypothesis: there are significant differences in the structural organization of such personal resources of coping behavior as indicators of optimism, self- 
efficacy, self-control, components of reflection, purposefulness and perseverance among high school students with different levels of stress resistance, was confirmed.

The obtained results of the study of the structural organization of the personal resources of coping behavior in high school students can become the basis for creating a training program for the development of personal resources of coping behavior by means of increasing the level of such personal qualities as optimism, purposefulness, situational reflection, and self-control.

\section{References}

1. D. Krok, B. Zarzycka, E. Telka, Risk of Contracting COVID-19, Personal Resources and Subjective Well-Being among Healthcare Workers: The Mediating Role of Stress and Meaning-Making. J. Clin. Med. 10(1), $132 \quad$ (2021) https://doi.org/10.3390/jcm10010132

2. N.V. Markina, E.L. Soldatova, I.L. Kachuro, A. Gavriliuc, Personal and existentialpsychological resources of form tutors working with gifted children. Obrazovanie i nauka-education and science, 23(1), 102-155 (2021) DOI: 10.17853/1994-5639-20211-102-135

3. V. A. Bodrov, Psychological stress: development and overcoming (Saratov: PER SE, IPR Media, Moscow, 2019)

4. M.A. Andersson, Identity Crises in Love and at Work: Dispositional Optimism as a Durable Personal Resource. Social psychology quarterly, 75(4), 290-309 (2012) DOI: 10.1177/0190272512451753

5. M.A. Kholodnaya, Intelligence, creativity, learning capability: Resource approach (on development of V. N. Druzhinin's ideas). Psychological Journal, 36(5), 5-14 (2015)

6. M. Archer, Making our way through the world: Human reflexivity and social mobility. Cambridge University Press, Cambridge (2007) https://doi.org/10.1017/CBO9780511618932

7. K.C. Myers, Reflexive Practice: Professional Thinking for a Turbulent World. Palgrave Macmillan, New York (2010) DOI: 10.1057/9780230112629

8. T. Golob, M. Makarovič, M. Rek, Meta-reflexividad para la resiliencia contra la desinformación. Páginas, 107-118 https://doi.org/10.3916/C66-2021-09

9. G. Uvarova, E. Krasnova, I. Mansurova, A. Korochentseva, E. Ezhak, Motivation sphere peculiarities of students with different reflexivity levels. 3rd International Multidisciplinary Scientific Conference on Social Sciences and Arts SGEM 2016 Sofia, 231-236 (2016) DOI: 10.5593/SGEMSOCIAL2016/B11/S01.030

10. Y.T. Glazunov, K.R. Sidorov, The degree of manifestation of volitional qualities as a measure of an ability to overcome obstacles in goal-achieving. Siberian journal of psychology, 61, 20-32 (2016) DOI: 10.17223/17267080/61/2

11. Ju. Rashupkina, O. Nikolenko, Specific features of students`personal maturity and personal immaturity depending on their social status. INTED 2017. 6300-6303 (2017)

12. D. Dautov, Procrastination and laziness rates among students with different academic performance as an organizational problem, E3S Web of Conferences, EDP Sciences, 210, 18078 (2020). https://doi.org/10.1051/e3sconf/202021018078

13. V. Capone, D. Caso, A. Rosa, Donizzetti and Fortuna Procentese niversity Student Mental Well-Being during COVID-19 Outbreak: What Are the Relationships between Information Seeking, Perceived Risk and Personal Resources Related to the Academic Context? Sustainability, 12, 7039 (2020). doi:10.3390/su12177039 
14. V. Capone, Il work-study conflict degli student universitari: Quali relazioni con il benessere? Psicol. Della Salut, 3, 131-144 (2018) DOI: 10.3280/PDS2018-003007

15. D. Guglielmi, A. Paplomatas, S. Simbula, M. Depolo, Prevenzioned ello stress lavoro correlato: Validazione di uno strumento per la valutazione dei rischi psicosociali nella scuola. Psicol. Della Salut., 3, 53-74 (2011) DOI: 10.3280/PDS2011-003003

16. S. Simbula, D. Guglielmi, W.B. Schaufeli, A three wave study on job resources, selfefficacy and work engagement among Italian school teachers. Eur. J. Work Organ. Psychol., 20, 285-305 (2011) DOI: 10.1080/13594320903513916

17. T. O. Gordeeva, E.N. Osin, D. D. Suchkov, T. Yu. Ivanova, O. A. Sychev, V. V. Bobrov, Self-Control as a Personality Resource: Assessment and Associations with Performance, Persistence and Well-Being. Cultural-historical psychology, 12(2), 46-58 (2016) DOI: 10.17759/chp.2016120205

18. K. Fujita, On conceptualizing self-control as more than the effortful inhibition of impulses. Personal. Soc. Psychol. Rev., 15, 352-366 (2011) doi: $10.1177 / 1088868311411165$

19. M. Inzlicht, J. N. Gutsell, Running on empty: neural signals for selfcontrol failure. Psychol. Sci., 18, 933-937(2007) doi: 10.1111/j.1467-9280.2007.02004.x

20. A. Korochentseva, E. Krasnova, O. Moysova, Simulation role play as a contact work with students and its role in their communicative skills development. Innovative Technologies in Science and Education (ITSE-2020) E3S Web of Conferences 210, 18087 (2020) https://doi.org/10.1051/e3sconf/202021018087

21. M. Inzlicht, K. M. Werner, J. Briskin, B. Roberts, Integrating Models of SelfRegulation. Annual Review of Psychology, 72, 319-345 (2020) DOI: 10.1146/annurevpsych-061020-105721

22. D. T. de Ridder, B. J. de Boer, P. Lugtig, A. B. Bakker, E. A. van Hooft, Not doing bad things is not equivalent to doing the right thing: distinguishing between inhibitory and initiatory self-control. Personal. Individual Differ, 50, 1006-1011 (2011) doi: 10.1016/j.paid.2011.01.015

23. D. T. de Ridder, G. Lensvelt-Mulders, C. Finkenauer, F. M. Stok, R. F. Baumeister, Taking stock of self-control: a meta-analysis of how trait selfcontrol relates to a wide range of behaviors. Personal. Soc. Psychol. Rev., 16, 76-99 (2012) doi: 10.1177/1088868311418749;

24. R. F. Baumeister, Self-regulation, ego depletion, and inhibition. Neuropsychologia, 65 , 313-319 (2014). doi: 10.1016/j.neuropsychologia.2014.08.012

25. M. Gillebaart, The "operational" definition of self-control. Front. Psychol., 9, 1231 (2018) doi: 10.3389/fpsyg.2018.01231

26. W. Hofmann, R. F. Baumeister, G. Förster, K. D. Vohs, Everyday temptations: an experience sampling study of desire, conflict, and self-control. J. Personal. Soc. Psychol., 102, 1318 (2012) doi: 10.1037/a0026545

27. J.P. Bermudez, The skill of self-control. SYNTHESE (2021) DOI: 10.1007/s11229021-03068-w

28. A. Shenhav, M.M. Botvinick, J.D. Cohen, The Expected Value of Control: An integrative theory of anterior cingulate cortex function. Neuron, 79(2), 217-240 (2013)

29. J.B. Li, I.T.Y. Leung, Z.X. Li, The pathways from self-control at school to performance at work among novice kindergarten teachers: The mediation of work engagement and work stress. Children and youth services review, 121, 105881 (2021) DOI: $10.1016 /$ j.childyouth.2020.105881 
30. A.L. Duckworth, P.D. Quinn, Development and validation of the Short Grit Scale (Grit-S). J. Personal. Assess, 91, 166-174 (2009)

31. M. Credé, M.C. Tynan, P.D. Harms, Much ado about grit: A meta-analytic synthesis of the grit literature. J. Person. Soc. Psychol., 113, 492-511 (2017)

32. L. Rey, C. Quintana-Orts, S. Mérida-López, N. Extremera, The Relationship between Personal Resources and Depression in a Sample of Victims of Cyberbullying: Comparison of Groups with and without Symptoms of Depression. Int. J. Environ. Res. Public Health, 17(24), 9307 (2020) https://doi.org/10.3390/ijerph17249307

33. H. A. Petrova, O.O. Zavarzina, I.P. Kytianova, R.V. Kozyakov, Social and personal factors of stable remission for people with drug addictions. Psychology in russia-state of the art., 8(4), 126-138 (2015) DOI: 10.11621/pir.2015.0411

34. E. Suroedova, G. Uvarova, N. Shevkieva, Structural organization of personal resources of coping behavior of students with different levels of self-organization of activity. E3S Web Conf. Innovative Technologies in Science and Education (ITSE2020), 210, 19005 (2020) https://doi.org/10.1051/e3sconf/202021019005

35. S. A. Khazova, Personal resources in adulthood. VOPROSY PSIKHOLOGII. 6, 28(2015)

36. G.M. Alarcon, N.A. Bowling, S. Khazon, Great expectations: A meta-analytic examination of optimism and hope. Personality and Individual Differences, 54, 821827 (2013) http://dx.doi.org/10.1016/j.paid.2012.12.004.

37. M.S. Hagger, K. Hamilton, Grit and self-discipline as predictors of effort and academic $\begin{array}{llllll}\text { attainment. Br. J. Educ. Psychol., 89, 324-342 (2019) } & \end{array}$ https://doi.org/10.1111/bjep.12241

38. J. Guo, X. Tang, K.M. Xu, Capturing the multiplicative effect of perseverance and passion: Measurement issues of combining two grit facets. Proc. Natl. Acad. Sci. USA., 116, 3938-3940 (2019) 10.1073/pnas.1820125116

39. E. H. Hernández, J.A. Moreno-Murcia, L. Cid, D. Monteiro, F. Rodrigues, Passion or Perseverance? The Effect of Perceived Autonomy Support and Grit on Academic Performance in College Students. Int. J. Environ. Res. Public Health, 17, 2143 (2020) doi:10.3390/ijerph17062143 